\title{
Light-actuated microrobots for biomedical science
}

\author{
Glückstad, Jesper; Villangca, Mark Jayson; Palima, Darwin Z.; Bañas, Andrew
}

Published in:

SPIE Newsroom

Link to article, DOI:

$10.1117 / 2.1201701 .006860$

Publication date:

2017

Document Version

Publisher's PDF, also known as Version of record

Link back to DTU Orbit

Citation (APA):

Glückstad, J., Villangca, M. J., Palima, D. Z., \& Bañas, A. (2017). Light-actuated microrobots for biomedical science. SPIE Newsroom. https://doi.org/10.1117/2.1201701.006860

\section{General rights}

Copyright and moral rights for the publications made accessible in the public portal are retained by the authors and/or other copyright owners and it is a condition of accessing publications that users recognise and abide by the legal requirements associated with these rights.

- Users may download and print one copy of any publication from the public portal for the purpose of private study or research.

- You may not further distribute the material or use it for any profit-making activity or commercial gain

- You may freely distribute the URL identifying the publication in the public portal

If you believe that this document breaches copyright please contact us providing details, and we will remove access to the work immediately and investigate your claim. 


\section{Light-actuated microrobots for biomedical science}

Jesper Glückstad, Mark J. Villangca, Darwin Z. Palima, and Andrew R. Bañas

Light can be used to fabricate, handle, power, and actuate microrobotics functionalities, such as the loading and unloading of micro-cargo, showing promise for drug delivery and biological-testing applications.

Light is an important research tool. It enables us to see things at a range of scales, from the macroscopic to the microscopic (where our own cells, bacteria, and other microorganisms proliferate). A less familiar property of light is the momentum that it carries. This feature enables focused light to trap, move, and position microscopic objects. ${ }^{1}$ This has had significant implications, particularly in biomedical science, by enabling researchers to use light to extend their 'hands,' and manipulate biological samples with great precision. Additionally, optical forces are non-invasive (because of their pico-Newton magnitude) and can operate through sealed and sterile biological chambers.

In addition to exploiting momentum to trap and move objects, light can now be used to generate secondary effects, such as heat. Previously, local heating in a microfluidic environment was achieved by using metal surfaces and metallic nanoparticles. These methods have enabled valve action, ${ }^{2}$ flow control, ${ }^{3}$ and mixing. ${ }^{4}$ They can also operate as catalysts for chemical reactions, ${ }^{5}$ and have even been applied for cancer therapy. ${ }^{6}$ However, a limitation faced when using metal layers in microfluidic devices arises because they are usually fixed to a certain region. In contrast, the motion and position of nanoparticles are difficult to control.

To solve this maneuverability problem, we have integrated metallic structures into a new type of light-driven microrobot. Recent improvements in the fields of optical manipulation and microfabrication can cater to increasingly sophisticated objects. We leveraged these developments to create new functional robotic tools for light-based microbiological experiments.

We employed a custom-fabrication technique, known as twophoton polymerization, to achieve 3D microprinting. In this process, focused laser beams are used to solidify a liquid polymer resin, achieving printed feature sizes of down to a fraction of the

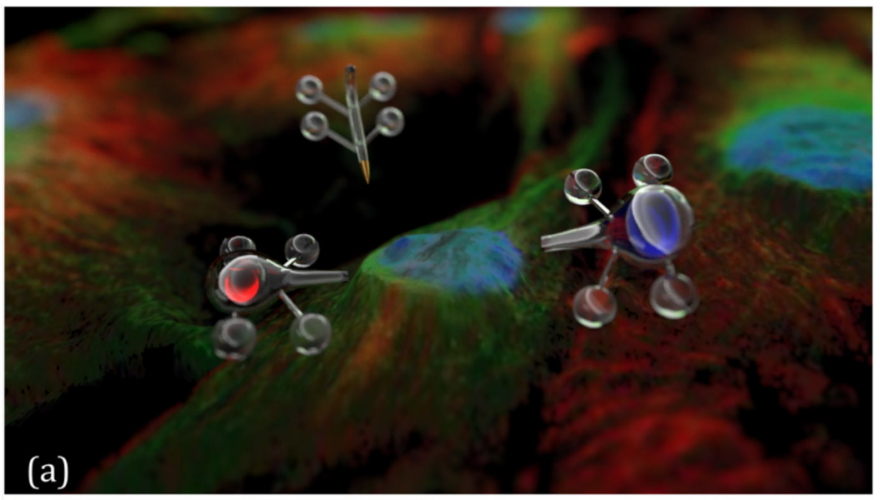

(b)
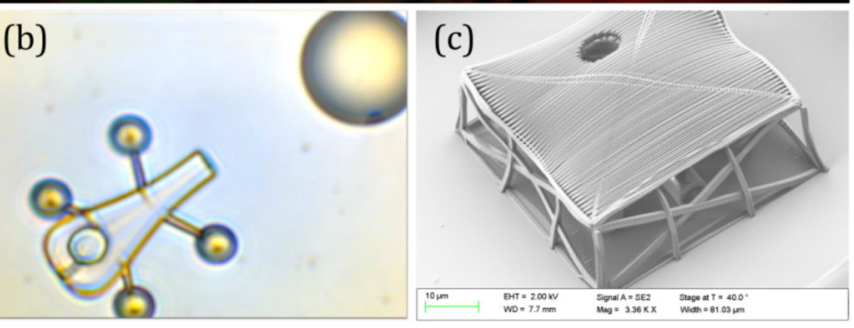

Figure 1. (a) An artist's rendition of a multitude of light-driven microrobots working together to probe a cell. (b) A hollow microrobot, designed for material transport, interacting with an oil droplet. (c) Scanning electron microscope image of the hollow microrobot. A mask is fabricated on top of the structure to secure exposure of only certain regions by metal-vapor deposition.

writing wavelength. As with 3D printers, different designs can be fabricated to perfectly suit particular applications. The structures that we have designed and demonstrated include waveguided optical waveguides ${ }^{7}$ (WOWs) and, more recently, hollow microrobots for material transport, as illustrated in Figure 1. Furthermore, light-initiated physical reactions enable new functionalities in these optical microrobots. ${ }^{8}$ Among the functionalities that we have incorporated, a syringe action enables the optical microrobots to load and unload a tiny cargo, making them capable of material transport. ${ }^{8}$

The photoresist that we use in the fabrication of these light

Continued on next page 
robots is practically transparent to the trapping beam wavelength and thus generates very little heat. Metals are efficient energy-to-heat converters of light so, to enhance laser-induced heat generation in the polymerized light robots, we embedded a thin metallic layer inside each of the light robots by using vapor deposition. For this purpose, we deposited a titanium adhesion layer and a gold layer (of 1 and 5nm thickness, respectively) as a circular disk inside the body of each light robot.

Once the microrobots are introduced into a cytometry cuvette, they are individually maneuverable using four counterpropagating beams that trap each of the spherical handles. Further, an extra beam is used for controlled heating of the internal metallic layer. Sufficient laser heating forms a microbubble around which strong convection currents are generated. The results of our experiments, shown in Figure 2, demonstrate that the convection currents can draw $2 \mu \mathrm{m}$-diameter silica beads into the structure. By combining convection currents with optical manipulation, each microrobot is made capable of picking up cargo at different locations. The hydrodynamic effect that is used to move particles can be quite strong and, in contrast to optical trapping and manipulation, does not rely on the refractive-index contrast.

Micro-cargo can subsequently be ejected by moving the heating beam across the body of the micro-tool, as shown in Figure 3. Many interesting phenomena can be observed here, such as thermo-capillary bubble migration, ${ }^{9}$ a directional change of the thermal gradient, ${ }^{10}$ and reversal of Marangoni convection (due to the presence of many particles). ${ }^{11} \mathrm{~A}$ video presentation of our recent results, published in Nature, is available online. ${ }^{12}$

In summary, we have developed optical microrobots with a
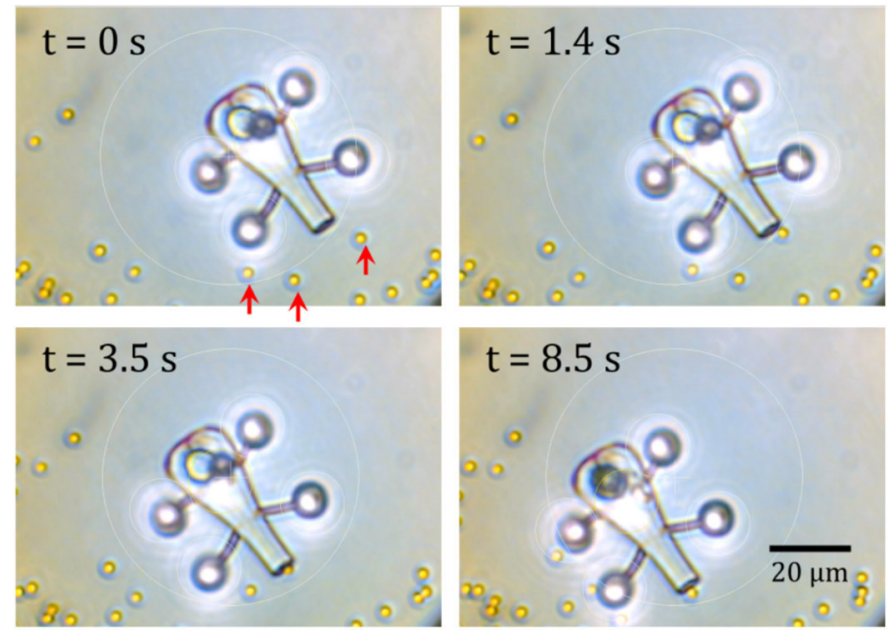

Figure 2. A hollow microrobot uses the generated convection current from a shaped laser beam targeted on the metallic layer to pull in $2 \mu \mathrm{m}$ diameter silica beads. ${ }^{8}$
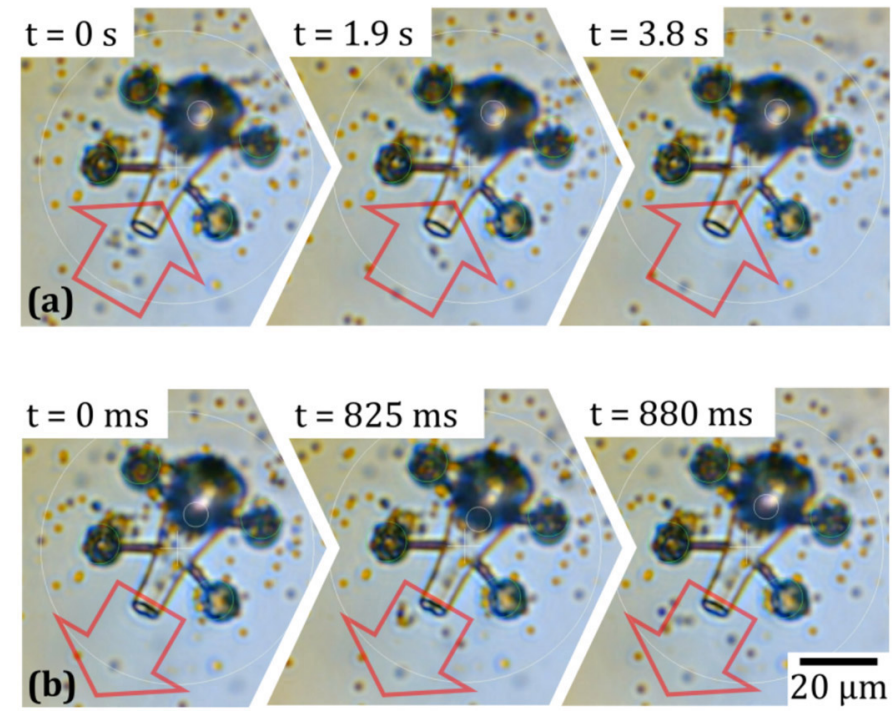

Figure 3. (a) A collection of $1 \mu \mathrm{m}$-diameter polystyrene beads are loaded inside a microrobot because of convection currents and (b) ejected by moving the heating beam across the body of the microrobot. ${ }^{8}$

variety of novel capabilities and features. Among these, the ability to optically control loading and unloading could have potential use in new drug-delivery approaches for single-cell experiments. Our light-driven microrobots can also be used to provide physical and chemical stimuli to biological samples. This control is not limited to a single robot and could potentially extended to a large handful by using advanced software (i.e., swarm robotics), thereby enabling microrobots to mutually coordinate to unveil new ways of interacting, probing, and acquiring information (e.g., for 3D microbiology). Ultimately, we forecast that light robotics will lead to completely new and disruptive schemes for real-time 3D interactions with the microscopic world. ${ }^{12,13}$ In our future work we will be investigating a range of applications for light robotics, particularly those relating to nanobiophotonics. ${ }^{14}$

We acknowledge support from the Innovation Fund Denmark under the project Enhanced Spatial Light Control in Advanced Optical Fibres. 


\section{Author Information}

Jesper Glückstad, Mark J. Villangca, and Darwin Z. Palima

Deptartment of Photonics Engineering

Technical University of Denmark

Kgs. Lynsby, Denmark

Jesper Glückstad is currently a professor at DTU Fotonik. Previously, he was a guest professor of biophotonics at the Lund Institute of Technology (2006-2011). He established the Programmable Phase Optics group and labs (PPO.dk) in the late 1990s, received the Danish Optical Society Award in 2000, and was elected Scientist of the Year 2005 by Ib Henriksen's Foundation in Denmark. He is a Fellow of SPIE and OSA.

Mark J. Villangca finished his MSc in physics at the University of the Philippines, where he worked on beam shaping using computer-generated holograms. He subsequently completed his $\mathrm{PhD}$ in photonics engineering at the Technical University of Denmark as a member of the Programmable Phase Optics group, working on light-driven microrobots. He also works with generalized phase contrast and digital holography for beam shaping.

Darwin Z. Palima is an associate professor at DTU Fotonik. He achieved his PhD in physics from the University of the Philippines and then moved to Denmark to work as a postdoctoral student. He has co-authored a book on generalized phase contrast and actively publishes in peer-reviewed journals and conference proceedings. He currently teaches biophotonics and optical engineering while pursuing his research interests, including computer-generated holograms, generalized phase contrast, optical trapping and micromanipulation, microscopy, and biophotonics applications.

\section{Andrew R. Bañas}

OptoRobotix ApS

Kgs. Lynsby, Denmark

Andrew R. Bañas earned his PhD from DTU Fotonik. His work with the Programmable Phase Optics group, including applying Fourier optics or electrodynamics to get the most out of experiments, has been featured in Optics Express and OPN. He has also designed and built hardware and software for beam shaping and optical-manipulation systems. He is currently pursuing tech-transfer activities, including the applications of generalized phase contrast and cell sorting for studying disease.

\section{References}

1. A. Ashkin, J. M. Dziedzic, J. E. Bjorkholm, and S. Chu, Observation of a single-beam gradient force optical trap for dielectric particles, Opt. Lett. 11, pp. 288-290, 1986.

2. K. Zhang, A. Jian, X. Zhang, Y. Wang, Z. Li, and H. Tam, Laser-induced thermal bubbles for microfluidic applications, Lab Chip 11, pp. 1389-1395, 2011. doi:10.1039/c0lc00520g

3. G. L. Liu, J. Kim, Y. Lu, and L. P. Lee, Optofluidic control using photothermal nanoparticles, Nat. Mater. 5, pp. 27-32, 2006. doi:10.1038/nmat1528

4. X. Miao, B. K. Wilson, and L. Y. Lin, Localized surface plasmon assisted microfluidic mixing, Appl. Phys. Lett. 92, 2008. doi:10.1063/1.2901192

5. C. Vázquez-Vázquez, B. Vaz, V. Giannini, M. Pérez-Lorenzo, R. A. AlvarezPuebla, and M. A. Correa-Duarte, Nanoreactors for simultaneous remote thermal activation and optical monitoring of chemical reactions, J. Am. Chem. Soc. 135, pp. 1361613619, 2013. doi:10.1021/ja4051873

6. N. S. Abadeer and C. J. Murphy, Recent progress in cancer thermal therapy using gold nanoparticles, J. Phys. Chem. C 120, pp. 4691-4716, 2016. doi:10.1021/acs.jpcc.5b11232

7. D. Palima, A. R. Bañas, G. Vizsnyiczai, L. Kelemen, P. Ormos, and J. Glückstad, Wave-guided optical waveguides, Opt. Express 20, pp. 2004-2014, 2012.

8. M. J. Villangca, D. Palima, A. R. Bañas, and J. Glückstad, Light-driven micro-tool equipped with a syringe function, Light Sci. Appl. 5, p. e16148, 2016. doi:10.1038/1sa.2016.148

9. D. W. Berry, N. R. Heckenberg, and H. Rubinsztein-Dunlop, Effects associated with bubble formation in optical trapping, J. Mod. Opt. 47, pp. 1575-1585, 2000. doi:10.1080/09500340008235124

10. A. Karbalaei, R. Kumar, and H. J. Cho, Thermocapillarity in microfluidics-a review, Micromachines 7, pp. 1-41, 2016. doi:10.3390/mi7010013

11. L. Lin, X. Peng, Z. Mao, W. Li, M. N. Yogeesh, B. B. Rajeeva, E. P. Perillo, A. K. Dunn, D. Akinwande, and Y. Zheng, Bubble-pen lithography, Nano Lett. 16, pp. 701708, 2015. doi:10.1021/acs.nanolett.5b04524

12. Rendition showing a small swarm of light-actuated micro-robots interacting with a cell. The insets shows experimental results with light-actuated micro-robots performing loading and unloading of cargo. http://tinyurl.com/zzq8th3 Credit: Mark Jayson Villangca. DTU Fotonik.

13. D. Palima and J. Glückstad, Gearing up for optical microrobotics: micromanipulation and actuation of synthetic microstructures by optical forces, Laser Photon. Rev. 7, pp. 478-494, 2013. doi:10.1002/lpor.201200030

14. J. Glückstad and D. Palima, Light Robotics - Structure-mediated Nanobiophotonics, $1^{\text {st }}$ ed., Elsevier, 2017. 